\title{
Operant conditioning of head turning in four-month infants
}

\begin{abstract}
Abstraet
Operant conditioning of head turning in 4-mo. human infants was demonstrated. Head rotations to the right or left of a central position were selectively strengthened by experimental presentation of milk as a reinforcing stimulus. Reliable acquisition and extinction of left or right rotations were found for two experimental groups while a control group for eliciting effects of milk presentation showed no consistent changes over conditioning phases.

\section{Introduction}

The current status of operant work with children in the first year of life has been evaluated in a recent review (Lipsitt, 1963) of the experimental investigations in this area. Some of these investigators (e. g., Brackbill, 1958; Rheingold et al., 1959; Weisberg, 1963) explored the use of operant techniques with infants as young as $3 \mathrm{mo}$. old, demonstrating conditioning by using a complex reinforcing stimulus consisting of auditory, visual, and tactile components. However, further development of operant procedures with infants in their first months of life has confronted researchers with two major problems; (1) identification of responses in the infant's behavior which can be quantified and automatically recorded; and (2) identification of reinforcing stimuli which can be manipulated experimentally in a laboratory setting.

A series of recent studies by Papousek $(1959,1960)$, using a combination of classical and operant techniques to study the head turning response in infants, suggested the possibility of exploring this response within an operant framework. The present study represents the first of several in progress investigating the head rotation response in infants.

\section{Method}

The Ss were three groups of 10 infants, approximately 120 days old, participating in an on-going Child Development Study. ${ }^{2}$ They were studied between 1w) and 11:30 a.m., and between 1:30 and 3 p.m., from 60 to $180 \mathrm{~min}$. after last feeding.

The apparatus consisted of a commercially-made infant reclining-seat on which was mounted a head cradle, constructed of light-weight plastic and lined with foam plastic. The cradle was adjustable for individual head size and body length. A potentiometer circuit recorded changes in potential, occurring with head rotations, on a Model 5 Grass Polygraph. Sensitivity on the polygraph was set to give directional deflections of $15 \mathrm{~mm}$ from baseline with $45^{\circ}$ rotations of the head cradle to the right or left from a central (neutral) position. In this study a head turn was defined as a rotation of 450 or greater to the right or left of the central position (maximum turn of $90^{\circ}$ ). A sighting device on the head cradle allowed $\mathrm{E}$ to

\section{Einar R. Siqueland ${ }^{\prime}$ BROWN UNIVERSITY}

discriminate rotations in excess of $45^{\circ}$ without reference to the polygraph record. Agreement between visual discriminations of $45^{\circ}$ turns and pen deflections of $15 \mathrm{~mm}$ was essentially perfect.

An experimental chamber, measuring $36 \times 30 \times 40$ in, constructed of white enameled plywood, standing $3 \mathrm{ft}$ above the floor, and open on one side, provided Ss with an environment devoid of distracting visual stimuli during conditioning procedures. The Ss were secured in the infant-seat and placed in the chamber, facing the blank white walls and ceiling, with their backs toward the open end of the box. The E and parent stood directly behind the infant's head at the open end of the chamber, outside the S's visual field. During conditioning procedures a nursing bottle could be presented by $\mathrm{E}$ from behind the $\mathrm{S}$, and each presentation was registered on the polygraph record by an event marker activated with a foot switch.

An 8-min. conditioning procedure was used which consisted of the following: 1-min. baseline, 3-min. conditioning, 2-min. extinction, and finally a 2-min. reconditioning period. The reinforcing stimulus was the presentation of a nursing bottle containing milk to the S's mouth for a 3-sec. interval. For Group R+ the reinforcing stimulus was presented immediately following each head turn of $45^{\circ}$ to the right. Group $\mathrm{C}$ provided control for the arousal and/or eliciting effect of milk presentation on head rotations. Individual control $\mathrm{Ss}$ were matched with experimental $\mathrm{Ss}$ in Group $\mathrm{R}+$ on number of milk presentations over conditioning and reconditioning phases, but milk presentation was not contingent upon turning to the right. Rather, the bottle was presented according to a randomized schedule for these infants. A third group of infants, Group L+ received the nursing bottle contingent upon head rotation of $45^{\circ}$ to the left.

Following each head turn, Ss' heads were recentered by $\mathrm{E}$. For the two experimental groups, if $\mathrm{S}$ failed to emit a $45^{\circ}$ turn in the specified direction over the first $30 \mathrm{sec}$. of conditioning, an attempt was made to shape the response by reinforcing turns of a smaller magnitude. However, only emitted head turns in excess of $45^{\circ}$ were recorded as responses. Group $\mathrm{R}+$ required virtually no shaping of the right turning response, while occasionally shaping of the left turn response was required for Group L + .

\section{Results}

The results for the three groups are summarized in Fig. 1. A Kruskal-Wallis one-way analysis of variance showed no significant difference between baseline response levels of right or left head turning for the three experimental groups. To test for evidence of typical acquisition and extinction effects of 


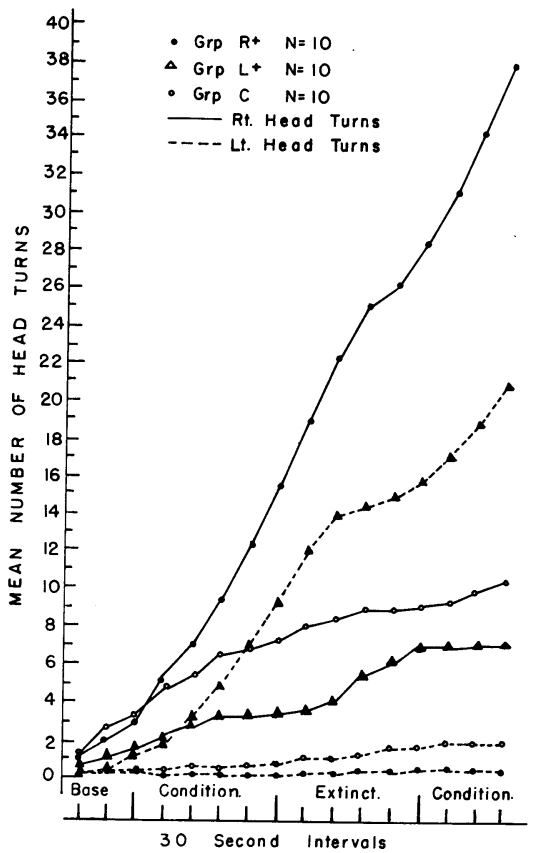

Fig. 1. Cumulative curves showing the mean response rate of right turns and left turns, for the three experimental groups, for $30-\mathrm{sec}$. periods during baseline, conditioning, extinction and reconditioning phases.

conditioning procedures, a series of Wilcoxon-matchedpairs signed-ranks tests were used to analyze shifts in number of head turns within each group over the conditioning phases. Group $\mathrm{R}+$ demonstrated a significant increase in head turns to the right between baseline and third minute of conditioning $(p<.025)$ and between baseline and first minute of extinction $(p<.005)$, a decrease between first and second minutes of extinction $(p<.005)$, and subsequently an increase in right turns between the second extinction minute and last minute of reconditioning $(p<.005)$. Group $L+$ and Group $\mathrm{C}$ failed to show any significant shifts in right head turning over these conditioning phases. A similar analysis of shifts in number of head rotations to the left yielded no significant changes for Group $\mathrm{R}+$ and Group C over these comparisons. On the other hand, Group $L+$ shifted significantly $(p<.01)$ in number of left turns on each of the four comparisons.

A final analysis of the data determined whether Group $\mathrm{R}+$ differed from Ss who received random presentations of a milk bottle, Group C, in number of right turns emitted during basal, conditioning, extinction and reconditioning phases of the experiment. Mann-Whitney U Tests yielded no significant differences for baseline response levels, or between response levels during the second minute of extinction, but predicted significant difference was found for the third conditioning minute $(p<.001)$ for the first minute of extinction $(p<.002)$, and for the last minute of the reconditioning phase $(p<.002)$.

\section{Diseussion}

In the design of this study, Group $\mathrm{C}$ provided a control for arousal and/or elicing effects of milk presentation upon the head turning response. Although Ss in the control group received the same number of reinforcements as infants in Group $\mathrm{R}+$, milk was presented in a random noncontingent manner. Comparisons between these two groups clearly indicate that the reliable acquisition and extinction of a right head turning response for Group $\mathrm{R}+$ cannot be attributed to the arousal or eliciting effects of the reinforcing stimulus.

Furthermore, the data from this study demonstrate that direction of turning (right vs left) can be strengthened selectively through differential reinforcement. A preliminary investigation had shown consistently higher base-rate for turning right as compared with left turns across a group of 4-mo. infants. Examination of the baseline data for the three groups in Fig. 1 supports this previous finding. However, despite the relatively low base-rate for left turns in this population of 4-mo. infants, the results for Group L+ demonstrate reliable acquisition and extinction of the left turn response. Examination of the learning curve for this group reflects differentiation of left head turns from right turning as a function of reinforcing contingencies during conditioning and extinction phases.

These results show that the head turning response in 4-mo. infants can be brought under operant control when brief presentation of a standard nursing bottle is used as a reinforcing event. Under the mild deprivation conditions of this study, the experimental procedures appeared to be minimally aversive to Ss. Generally, procedures could be completed without eliciting crying or other aversive behavior. On the basis of these results, further use is being made of these techniques in studying discriminative and learning processes in the young infant.

\section{References}

BRACKBILL, YVONNE. Extinction of the smiling response in infants as a function of reinforcement schedule. Child Developm., 1958, 29, 115-124.

LIPSITT, L. P. Learning in the first year of life. In L. P. Lipsitt \& C. C. SPIKER (Eds.), Advances in child development and behavior. New York: Academic Press, 1963. Pp. 147-195.

PAPOUSEK, H. A method of studying conditioned food reflexes in young children up to the age of six months. Pavlov J.higher nerv. Activ., 1959, 9, 136-140.

PAPOUSEK, H. Conditioned head rotation reflexes in infants in the first months of life. Acta Pediatr., 1961, 50, 565-576.

RHEINGOLD, HARRIET L., GEWIRTZ, J. L., \& ROSS, HELEN W. Social conditioning of vocalizations in the infant. J.comp. physiol. Psychol., 1959, 52, 68-73.

WEISBERG, P. Social and nonsocial conditioning of infant vocalizations. Child Developm., 1963, 34, 377-388.

\section{Notes}

1. This research was conducted while the author was a Postdoctoral Fellow of the United States Public Health Service. It was supported in part by a USPHS research grant (No. NB-04268) to Lewis P. Lipsitt, whose valuable advice during the course of this investigation is gratefully acknowledged.

2. National Collaborative Project of the National Institute of Neurological Diseases and Blindness. 